\title{
A case of paternally inherited congenital myotonic dystrophy
}

Masanori Nakagawa, Hirohisa Yamada, Itsuro Higuchi, Yoshio Kaminishi, Tetsuro Miki, Keith Johnson, Mitsuhiro Osame

\begin{abstract}
We report two sisters with congenital myotonic dystrophy (CDM) born to a normal mother and an affected father. The congenitally affected daughters had symptoms from birth. The age of onset of $D M$ in the father was 39 years. Analysis of the CTG trinucleotide expansion in this family showed increase in the repeat length with increasing severity, with the smallest expansion in the grandfather and the largest expansion in the younger of the two CDM sisters. This family shows that exceptionally it is possible for CDM to be inherited paternally and refutes the hypothesis that CDM is exclusively of maternal origin. This contradicts several of the previous hypotheses concerning the mechanisms by which the CDM phenotype arises.
\end{abstract}

( $\mathcal{F}$ Med Genet 1994;31:397-400)

Myotonic dystrophy (DM) is the commonest cause of inherited adult muscular dystrophy. Usually it progresses slowly over several decades and affects many of the organ systems of the body. The commonest presenting symptoms are myotonia, muscular atrophy, cataract, and endocrine dysfunction. ${ }^{1}$ Families in which the disorder segregates as an autosomal dominant disorder have three distinct classes of affected subjects: late onset (mild), classical or adult onset (moderate to severe), and congenital cases (very severe).

The mutation underlying DM was recently identified by a positional cloning approach ${ }^{2-4}$ and shown to result from expansion of a $(\mathrm{CTG})_{\mathrm{n}}$ trinucleotide repeat in the $3^{\prime}$ untranslated region of a gene encoding a putative protein kinase..$^{5-7}$ This mutation is unstable in nearly all generations and explains the observation of anticipation in families in which DM is segregating. ${ }^{8}$ The most severe form of the phenotype, congenital myotonic dystrophy $(C D M)$, results in significant fetal loss and death in the perinatal period. ${ }^{9}$ Transmission of this form of the disease has only ever been seen from mothers and several hypotheses have been put forward to explain this, including genomic imprinting, ${ }^{10}$ and the existence of a maternal intrauterine factor. ${ }^{11}$ Recently it has been shown that the mouse homologue of the DM gene does not undergo imprinting. ${ }^{12} \mathrm{By}$ showing in this paper that a father can transmit the congenital form of the disease to his offspring, we rule out the requirement of an intrauterine factor in the aetiology of this form of the disease.

\section{Case reports}

CASE 1

Case 1 was a 10 year old girl with facial diplegia and mental retardation (IQ $<40$, WISC). She was a floppy infant born to a healthy 32 year old mother by spontaneous vaginal delivery at 40 weeks' gestation. The pregnancy was complicated by hydramnios. The child weighed $3200 \mathrm{~g}$ at birth and had severe hypotonia, feeding difficulties, weak respiration, and pes equinovarus. Her developmental milestones were delayed, she could not control her head in the sitting position until she was 1 year old, she needed nappies until the age of 4 , and started to walk at the age of 8 . She was diagnosed as having congenital myopathy, mental retardation, and Moebius syndrome at 1 year of age. At this time she underwent an operation on her Achilles tendon to correct her pes equinovarus.

At presentation she weighed $17 \mathrm{~kg}$ and was $118 \mathrm{~cm}$ tall. In addition to the previously mentioned symptoms she was found to have dysarthria, a nasal voice, an open bite, a high arched palate, diffuse muscle weakness with atrophy, pes equinovarus, and genu recurvatum. She was able to walk using a crutch and a fixed ankle short leg brace. Percussion myotonia was evident that had not been noted at the age of 8 . This was confirmed by electromyography (EMG). The electrocardiogram (ECG) showed absence of conduction block. The serum creatine kinase $(\mathrm{CK})$ was mildly raised $(51 \mathrm{mU} / \mathrm{ml}$, normal <40). Frontal lobe atrophy was seen on CT scan of the brain.

CASE 2

This 15 year old girl, the sister of case 1 , was born by normal vaginal delivery at 40 weeks' gestation and weighed $3500 \mathrm{~g}$ at birth. She was floppy, but respiratory failure and feeding difficulties were not reported. Her developmental milestones were normal. At the age of 3 her 


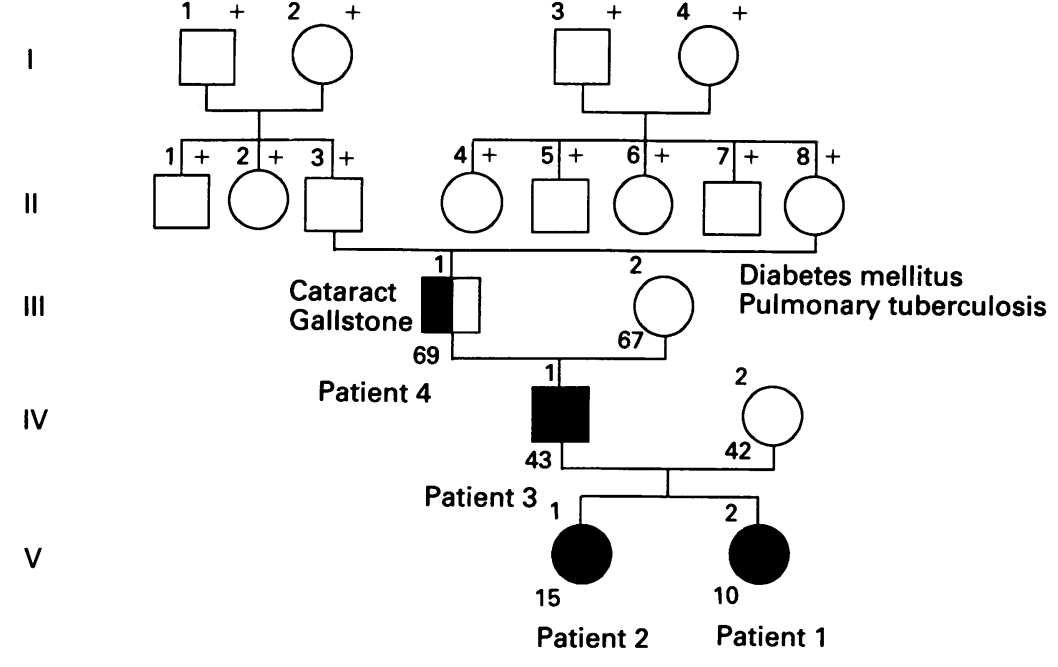

Figure 1 Pedigree of the DM family.

mother noticed that her mouth was always open and by the age of 10 she had difficulty opening a can and ran slowly.

At presentation she was $146 \mathrm{~cm}$ tall and weighed $38 \mathrm{~kg}$. She was found to be mentally retarded (IQ 55, WISC) and had mild facial muscle weakness, dysphagia, a nasal voice, scoliosis, and distal dominant muscle weakness with atrophy. Although able to walk she could not climb stairs. Her grip and percussion myotonia were obvious and myotonic discharges were evident on the EMG. Her ECG was normal and her serum CK mildly raised $(85 \mathrm{mU} / \mathrm{ml})$. Frontal lobe atrophy and mild ventricular dilatation were seen on brain CT scan.

CASE 3

This 43 year old man is the father of patients 1 and 2. He complained of weakness of his fingertips at the age of 39 and observed weakness in his left leg at the age of 41. During high school he was good at rugby and boxed at college. He developed tinnitus at the age of 41 and a mild bilateral hearing impairment was detected by audiometry. He was $168 \mathrm{~cm}$ tall and weighed $60 \mathrm{~kg}$. There was no intellectual impairment. He presented with hatchet face, a nasal voice, and distal muscle weakness (hand grip $5 \mathrm{~kg}$ ). Myotonia could be shown clinically

Table 1 Clinical and laboratory findings in the DM family

\begin{tabular}{|c|c|c|c|c|}
\hline & \multicolumn{4}{|l|}{ Cases } \\
\hline & 1 & 2 & 3 & 4 \\
\hline Age/sex & $10 \mathrm{y} / \mathrm{F}$ & $15 \mathrm{y} / \mathrm{F}$ & $43 \mathrm{y} / M$ & $69 y / M$ \\
\hline Age of onset & At birth & At birth & 39 & - \\
\hline Height $(\mathrm{cm})$ & 118 & 146 & 168 & 163 \\
\hline Weight (kg) & 17 & 38 & 60 & 65 \\
\hline Mental retardation & $\mathrm{IQ}<40$ & $\mathrm{IQ}=55$ & - & - \\
\hline Muscle weakness & + & + & + & - \\
\hline Muscle atrophy & + & + & + & - \\
\hline Myotonia & + & + & + & - \\
\hline Serum CK level $(\mathrm{mU} / \mathrm{ml})^{*}$ & 51 & 85 & 175 & 46 \\
\hline Myotonic discharge & + & + & + & - \\
\hline Cardiac conduction block & - & $\bar{x}$ & - & - \\
\hline Brain CT scan & $\begin{array}{l}\text { Frontal } \\
\text { lobe atrophy }\end{array}$ & $\begin{array}{l}\text { Ventricular } \\
\text { dilatation }\end{array}$ & $\mathrm{NE}$ & NE \\
\hline Type 1 fibre atrophy & + & + & + & NE \\
\hline Increased central nuclei & - & - & + & NE \\
\hline
\end{tabular}

* Normal level of $\mathrm{CK}$ is less than $40 \mathrm{mU} / \mathrm{ml}$ in females and less than $55 \mathrm{mU} / \mathrm{ml}$ in males.

- absent or negative, + present or positive, $\mathrm{NE}=$ not examined. and by EMG and he had a raised serum $\mathrm{CK}$ $(175 \mathrm{mU} / \mathrm{ml}$, normal <55).

CASE 4

This man was the father of case 3 . He had cataracts but no muscle weakness or myotonia were demonstrable clinically or by EMG. He was suspected of being diabetic and had undergone cholecystectomy at the age of 53. The family pedigree is shown in fig 1 .

\section{Muscle pathology}

Open muscle biopsies of the biceps brachii were performed on cases 1, 2, and 3. Frozen sections showed an increase of central nuclei in case 3 that was not seen in cases 1 or 2 . All three of these patients had type 1 fibre atrophy. The clinical and laboratory findings are summarised in table 1 .

\section{DNA analysis of unstable region of the DM gene}

Genomic DNA samples of these four patients, the mother (IV.2) and the grandmother (III-2) were prepared from peripheral blood by conventional methods. ${ }^{13}$ DNA $(5 \mu \mathrm{g})$ was digested with BamHI or SacI in $50 \mu \mathrm{l}$ of reaction buffer and electrophoresed on $0.8 \%$ agarose gels. After Southern blotting of the DNA the nylon membrane was hybridised with digoxigenin labelled probe $\mathrm{p} 5 \mathrm{~B} 1.4^{14}$ at $42^{\circ} \mathrm{C}$ for 16 hours. After hybridisation the membrane was washed in $2 \times$ SSC, $0.5 \%$ SDS followed by $0.5 \times$ SSC, $0.5 \%$ SDS solution. Digoxigenin labelled DNA was detected by chemiluminescence (Boehringer Mannheim) and the membrane exposed to $x$ ray film. In both restriction digests expansions of $4 \mathrm{~kb}, 2 \cdot 7 \mathrm{~kb}$, and $600 \mathrm{bp}$ were detected in the DNA from cases 1,2 , and 3 , respectively (fig 2 ).

Genomic DNA from the family members in fig 1 was amplified using primers 101 and 102 or 96 and $102^{5}$ under the conditions described previously. ${ }^{15}$ cDNA containing five repeats was used as control and the size of the products determined on a sequencing gel with a sequence ladder as size marker. Using primers 96 and 102, bands of $200 \mathrm{bp}$ and $300 \mathrm{bp}$ were amplified from the DNA of case 4 compared to $160 \mathrm{bp}$ for the 5 CTG control. III. 2 generated bands of $200 \mathrm{bp}$ and $210 \mathrm{bp}$ and IV.2 bands of $160 \mathrm{bp}$ and $220 \mathrm{bp}$. Only a band of $220 \mathrm{bp}$ was amplified from the DNA of cases 1 and 2 and a band of $200 \mathrm{bp}$ was generated from the DNA of case 3 (fig 3 ).

Table 2 Manifestations of congenital myotonic dystrophy

\begin{tabular}{llll}
\hline & $\begin{array}{l}\% \text { in } \\
126 \text { cases }^{1}\end{array}$ & Case 1 & Case 2 \\
& $85 \cdot 7$ & + & + \\
\hline Facial weakness & $69 \cdot 8$ & + & + \\
Hypotonia & $64 \cdot 3$ & + & + \\
Delayed motor development & 62.7 & + & + \\
Mental retardation & $52 \cdot 4$ & + & - \\
Talipes & $47 \cdot 6$ & - & - \\
Neonatal respiratory distress & $57 \cdot 9$ & + & - \\
Neonatal feeding difficulty & $25 \cdot 4$ & + & - \\
Hydramnios & $22 \cdot 2$ & + & \pm \\
Reduced fetal movement & 22.2 & &
\end{tabular}




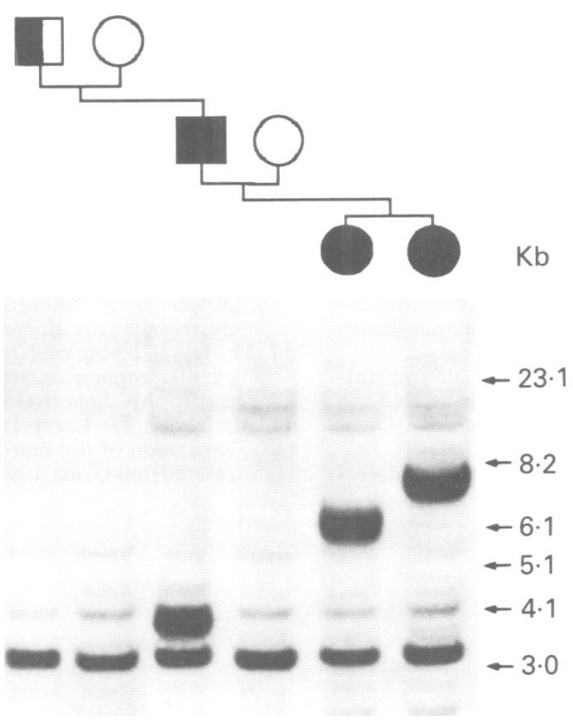

Sacl digestion

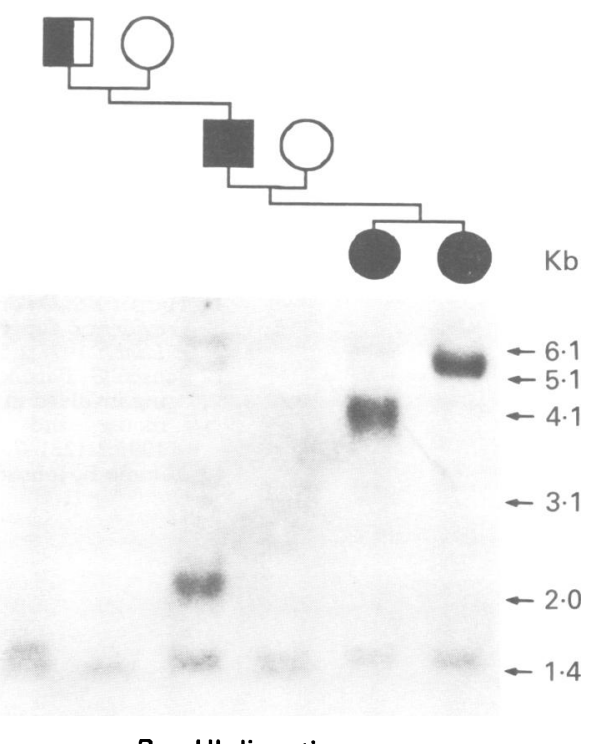

BamHI digestion

Figure 2 Pedigree and Southern blot (probe p5B1.4) analysis of three generations of the DM family.

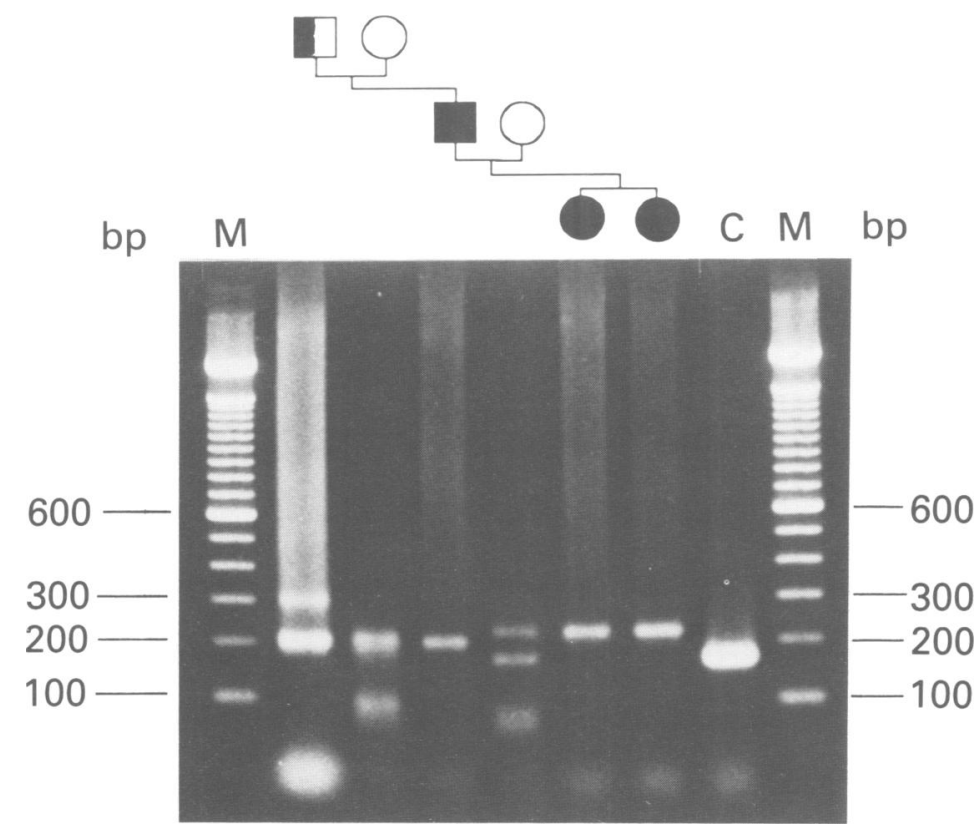

Figure 3 PCR products using primers 96 and 102 which flank CTG repeats. $C=c D N A$ containing five $C T G$ repeats $(160 \mathrm{bp}$ band $)$.

\section{Discussion}

The congenital form of DM is characterised by a number of different symptoms, differing combinations of which may be present in patients. These symptoms are listed in table 2 along with their presence or absence in cases 1 and 2 . While the symptoms in case 2 may be most consistent with a diagnosis of early onset $\mathrm{DM}$, those in case 1 fall clearly within the standard diagnosis of congenital DM. This is the first reported case of congenital presentation with transmission through the paternal line. This has important consequences both for genetic counselling and for understanding the mutational mechanism and aetiology of this disease.

The finding that congenital DM can be paternally transmitted, even if the incidence of such cases is very low, casts doubt upon certain mechanisms previously postulated to explain the maternal transmission of the congenital form of the disorder. Although both genomic imprinting ${ }^{10}$ and interaction with intrauterine factors ${ }^{11}$ have been suggested to account for the maternal transmission of the disorder, little if any direct evidence has been reported for either scenario and the data in this paper make these proposed mechanisms unlikely. It has been reported that the likelihood and extent of further amplification of the CTG expansion upon transmission is much greater for mothers than for fathers ${ }^{1617}$ and it has been suggested that very large expansions may be deleterious for sperm survival and function. ${ }^{18}$ The expansion in the congenitally affected child $(4 \mathrm{~kb})$ in this family is of a size rarely seen with paternal transmission, and represents a very large amplification of the paternal expansion $(0.6 \mathrm{~kb})$. Transmission of such large alleles by a male is very rare and it is possible that there are other factors, perhaps genetically determined (although not necessarily linked to the DM locus), which in a small number of cases may result in paternal transmission of congenital DM. The paternal transmission of the congenital disorder in this family suggests that the extent of the CTG repeat expansion may be the major influence on expression of the congenital phenotype.

We thank Dr R L Rosales for his critical reading of this manuscript, and Dr Nessa Carey for helpful discussions. We thank Ms Shoko Taniguchi for excellent technical assistance. Work at Kagoshima University is supported by Research Grant (2A-2) for Nervous and Mental Disorders from the Ministry of Medical School is supported by the MDG of Great Britain and The Central Research Fund of the University of London.

1 Harper PS. Myotonic dystrophy. 2nd ed. London: Saunders, 1989.

2 Aslanidis C, Jansen G, Amemiya C, et al. Cloning of the essential myotonic dystrophy region and mapping of the putative defect. Nature 1992;355:548-51.

3 Buxton J, Shelbourne P, Davies J, et al. Detection of an unstable fragment of DNA specific to individuals with myotonic dystrophy. Nature 1992;355:547-8.

4 Harley HG, Brook JD, Rundle SA, et al. Expansion of an unstable DNA region and phenotypic variation in myotonic dystrophy. Nature 1992;355:545-47.

5 Brook JD, McCurrach ME, Harley HG, et al. Molecular basis of myotonic dystrophy: expansion of a trinucleotide basis of myotonic dystrophy: expansion of a trinucleotide
(CTG) repeat at the $3^{\prime}$ end of a protein kinase family (CTG) repeat at the $3^{\prime}$ end of a protein kinase family
member. Cell 1992;68:799-808.

6 Fu YH, Pizzuti A, Fenwick RG, et al. An unstable triplet repeat in a gene related to myotonic muscular dystrophy, myotonin protein kinase. Science 1992;255:1256-8. 
7 Mahadevan M, Tsilfidis C, Sabourin L, et al. Myotonic dystrophy mutation. An unstable CTG repeat in the $3^{\prime}$
untranslated region of a candidate gene. Science untranslated regior

8 Howeler CJ, Busch HFM, Geraedts JPM, et al. Anticipation in myotonic dystrophy: fact or fiction. Brain tion in myoton

9 Harper PS. Congenital myotonic dystrophy in Britain. II. Genetic basis. Arch Dis Child 1975;50:514-21.

10 Hall JG. Genomic imprinting: review and relevance to human diseases. Am $\Im$ Hum Genet 1990;46:857-73.

11 Harper PS, Dyken PR. Early onset dystrophia myotonica evidence supporting a maternal environmental factor. evidence supporting

12 Jansen G, Bartolomei M, Kalscheuer V, et al. No imprinting involved in the expression of DM-kinase mRNAs in mouse and human tissues. Hum Molec Genet

13 Nimmo E, Johnson K. RFLPs: uses and methods of detec- tion. In: Dale JW, Sanders PG, eds. Methods in gene technology. London: JAI Press, 1991:267-83.

14 Shelbourne $P$, Wingvist $R$, Kunert E, et al. Unstable DNA may be responsible for the incomplete penetrance of the myotonic dystrophy phenotype. Hum Molec Genet 1992;1:467-73.

15 Davies J, Yamagata $H$, Shelbourne $P$, et al. Comparison of the myotonic dystrophy associated CTG repeat in European and Japanese populations. $f$ Med Genet pean and 1992;29:766-9.

16 Cobo AM, Baiget M, Lopez de Munain A, et al. Sex-related difference in intergenerational expansion of myotonic difference in intergenerational expan
dystrophy gene. Lancet 1993;341:1159.

17 Mulley JC, Staples A, Donnelly A, et al. Explanation for exclusive maternal origin for congenital form of myotonic exclusive maternal origin for congen

18 Abeliovich D, Lerer I, Pashut-Lauron I, et al. Negative expansion of the myotonic dystrophy unstable sequence. Am $\mathcal{F}$ Hum Genet 1993;52:1175-81. 